\title{
RELATORIO DAS ATIVIDADES DO INSTITUTO DE ESTUDOS BRASILEIROS \\ DA UNIVERSIDADE DE SÃO PAULO EM 1977.
}

- O Instituto de Estudos Brasileiros, criado pela Portaria GR no 5 de 09.01.63, ainda mantém sua estrutura e designação: o projeto de Regimento Interno do Instituto de Estudos Brasileiros, elaborado nos termos da Portaria GR n? 5, de 09.01.63, combinado com o disposto no Regimento Geral da Universidade de São Paulo, capítulo III, seções I e II - subseçōes I, II, III foi encaminhado, em agosto de 1975 , ao Magnífico Reitor, para apreciação final do Egrégio Conselho Técnico Administrativo da Universidade de São Paulo, quando então será enquadrado definitivamente na Reforma Universitária promulgada em janeiro de 1970. Continua, assim administrado por um Conselho de Administração de professores titulares das disciplinas de estudos brasileiros, que o integram, com um diretor e um vice-diretor, eleitos pelo Conselho e nomeados pelo Magnífico Reitor da Universidade de São Paulo.

- Diretoria

Diretor - Prof. Dr. José aderaldo Castello.

Vice-diretor - Prof. Dr. João Baptista Borges Pereira.

Secretaria - Funcionária responsável: Lic. Ivone Casseb Chamelet Nogueira.

Obs.: Como a Reestruturação do IEB ainda não se processou efetivamente, os serviços internos de Expediente, Protocolo, Arquivo, Almoxarifado e recep̧̧ão estão sob a responsabilidade da Secretária.

\section{- Outros Setores}

- Os demais serviços burocráticos são elaborados pela "Diretoria Administrativa" dos Institutos da Universidade de São Paulo.

- Biblioteca e Arquivo.

- Museu - "Coleção Mário de Andrade - I - Artes Visuais". 
- Setor de Pesquisa e Documentação.

- Setor Cultural - Cursos, Publicação, Intercâmbios.

- Conselho de Administração

o Conselho de Administração reuniu-se, regularmente, uma vez por mês, sob a presidência do Diretor do Instituto, Prof. Dr. José Aderaldo Castello. Tomou ciência de todos os atos da Diretoria, deliberou e propôs medidas de ordem administrativa, relativas a programas de pesquisas, cursos e conferências, intercâmbio e publicações, executadas pela Diretoria e pelos setores competentes.

- Além dos serviços rotineiros de administração, a Diretoria do IEB providenciou vários outros, relacionados a seguir.

- VI Curso de Férias sobre Cultura Brasileira, de 14 a 18 de fevereiro.

- Conferências realizadas pelo Prof. Jean ROCHE da Universidade de Toulouse, França, sobre João Cabral de Mello Neto e sobre o Romance Modernista.

- Aquisição de um mesanino, confeccionado em chapa de aço, em prolongamento ao existente, para ampliação da Biblioteca do IEB.

- Colaboração com o Centro de Estudos Rurais e Urbanos, sob a direção da Profa. Dra. Maria Isaura Pereira de Queiroz, para a pesquisa "Levantamento da Obra Brasileira de Roger Bastide" que constituirá o Arquivo Roger Bastide a ser organizado por este Instituto, para posterior publicação das "Obras Completas de Roger Bastide".

- Recep̧ão a vinte e quatro professores universitários americanos, Grupo Georges Consortium Brazil Faculty Development Seminar, ligados aos Estudos Brasileiros e liderados pelo Prof. Dr. Parke RENSHAW, de 26 de julho a 10 de agosto, em visita à Universidade de São Paulo.

- Cooperação com o Departamento de Bibliotecas Públicas da Prefeitura do Município de São Paulo para a realização da exposição "Mário, aprendiz de fotógrafo", comemorativa do nascimento de Mário de Andrade, em outubro.

- Publicação da Revista do Instituto de Estudos Brasileiros, no 19.

- Organizaçâo e patrocínio, juntamente com o Museu de Arte Contemporânea da Universidade de São Paulo, da Exposição Retrospectiva de Anita Malfatti, inaugurada dia 10 de novembro.

- Aquisição de aparelhos de uso permanente: uma furadeira B. Decker com jogo de brocas, trếs fichários, um arquivo de pasta suspensa, um aspirador de pó e vinte e quatro luminárias.

- Aquisição de materiais para acomodação e proteção das obras do Museu Mário de Andrade e reforma do mesmo.

\section{BIBLIOTECA E ARQUIVO}

\section{Biblioteca - Situação atual:}

Bibliotecárias responsáveis: D. Catharina Cristoforo, D. Maria Itália Causin e D. Rosemarie Erika Horch; Auxiliar de Biblioteca: Maria Gonçalves. Compõe-se a Biblioteca do Instituto de Estudos Brasileiros de sete seçōes, conforme critérios fixados em função do histórico de aquisição das coleçōes que a compōem.

- Coleçōes:

- "Coleção Brasiliana" - cujo núcleo é o acervo que pertenceu a Yan de Almeida Prado. Com esse núcleo somam-se as aquisições avulsas ou de pequenas coleções. E uma das brasilianas mais completas. 
Obras tombadas e em catálogo - 15.455 .

Manuscritos - 50.

- "Coleção Guerra do Paraguai", fixa.

Obras tombadas -323 títulos em 375 volumes.

- "coleção Lamego", fixa.

Obras tombadas e em catálogo -4.000 .

Manuscritos - 154 (835 códices).

- "coleção Mário de Andrade - II - Biblioteca", classificada.

Contém livros e periódicos: arte em geral e literatura, formando um dos mais completos conjuntos para o estudo do Modernismo.

Obras em catálogo - 17.000 .

- "Coleção Desembargador Juarez Bezerra", fixa.

Doação da viúva Juarez e filhos: Prof. Dr. Ulpiano Toledo Bezerra de Meneses, Dr.

José Bezerra de Meneses e a.Licenciada Adélia B. M. Bolle.

Total de -6.221 .

- "Coleção G. Rosa", fixa.

Contém documentos, correspondência e manuscritos diversos.

Obras -3.500 .

- "coleção José Feliciano de Oliveira" - classificada.

Contém livros e periódicos, sendo especializada em positivismo.

Total - 7.794.

- Movimento e atividades conjuntas das bibliotecárias Catharina Cristoforo, Maria Itália Causin e Rosemarie Erika Horch e da auxiliar de biblioteca Maria Gonçalves.

- Durante o ano de 1977, foram feitas várias aquisições de obras e periódicos, no sentido de ampliar e atualizar o acervo, especialmente para completar as coleções já existentes.

- Acervo Yan de Almeida Prado

- Livros

- Pesquisas bibliográficas - 2.036

- Classificação-671.

- Catalogação - 671 .

- Tombamento - 671 .

- Revistas

- Atualização do Kardex.

- Atualização do catálogo de periódicos para uso público.

- Atualização do catálogo de periódicos para uso das bibliotecárias.

- Catalogação

- Catalogação

- 75 títulos novos para catálogo de periódicos.

- 75 títulos novos para catálogo interno das bibliotecárias.

- 75 fichas para fichário cronológico.

- 75 fichas para fichário geográfico.

- 502 fichas para fichário de assuntos.

- Indexação

- Revista Debate e Crítica. 1973-1975, 1-6

- Indexaçẫo de autores: 58

- Indexação de títulos: 58

- Indexação de assuntos: 174 
- Revista Argumento.

1973-1974, 1-4

- Indexação de autores: 53

- Indexação de títulos: 53

- Indexação de assuntos: 169

- Outras atividades.

- Ofícios e cartas enviadas - 14.

- Ofícios de agradecimentos - 523.

- Memorando - 1 .

- Orientação bibliográfica a pesquisadores e colaboração com companhias editoras e outras instituições para serviços fotográficos de estampas e gravuras para ilustração de obras em preparo.

- Pesquisa de referências para o público.

- Bibliografias.

- Consultas ao Catálgogo Coletivo de Livros:157.

- Movimento da Biblioteca.

- Livros classificados -3.892 .

- Livros raros - 778.

- Mário de Andrade - 421.

- Lamego - 42.

- Juarez Bezerra - 34.

- Guimarães Rosa - 29.

- Guerra do Paraguai - 31.

- Revistas - 932 (títulos).

Obs.: A Biblioteca esteve fechada para o público de julho a outubro por motivo de reforma.

Arquivo - Situação Atual:

Responsável: Profa. Dra. Heloísa Liberalli Bellotto; Axuliar de Arquivo: José Alfredo Ornellas de Mello. $O$ Arquivo possui oito coleçōes, quase todas fundamentais para o estudo do Modernismo.

\section{MUSEU - "COLEÇĀO MARIO DE ANDRADE - I - ARTES VISUAIS"}

Consta de mais de 600 peças relativas à Arte Moderna, nacional e estrangeira: pintura, escultura, desenho e gravura. A parte relativa à arte brasileira cobre o período de 1917 a 1945 . Além disso, há peças de arte sacra, em número de setenta - época colonial - e algumas populares; peças de arte popular e folclóricas, como ex-votos e muitos objetos de artesanato relacionados com a Revoluçāo de 1932.

\section{SETOR DE PESQUISA E DOCUMENTAÇĀO}

Reúne pessoal especializado de nível universitário, distribuído por diversas áreas de estudos brasileiros, nas funçōes de historiógrafos.

I - AREA DE HISTORIA:

1. Atividade de Pesquisa da Profa. Dra. Arlinda Rocha Nogueira:

Pesquisa individual concluída: contribuição para o estudo da imigraçâo japonesa em 
Minas Gerais (1889/1930). Pesquisa individual em andamento: a) Imigração no Estado de São Paulo (1889/1922). Estudo das manifestaçōes da imprensa paulista com relaçäo à imigração japonesa e estabelecimento de comparaçōes com as tomadas de posição relativas às imigraçð̃es de outras procedências. b) Dados biográficos do Prof. Dr. Sérgio Buarque de Holanda. Pesquisa de grupo concluída: Levantamento dos manuscritos das coleções Lamego e J. F. de Almeida Prado relativos à história de São Paulo.

Colaboradora: Profa. Dra. Lucy Maffei Hutter. Pesquisa de grupo em andamento: a) Levantamento Bibliográfico de História e Economia brasileiras referente ao período de 1920/1960. Colaboradores: Prof. Dra. Lucy Maffei Hutter e Profa. Dra. Heloísa Liberalli Bellotto. b) Trabalho sobre a Toponímia do Rio Tietê. Colaborador: Prof. Dr. Carlos Drumond.

\section{Atividade de Pesquisa da Profa. Dra. Heloísa Liberalli Bellotto.}

Pesquisa individual concluída: a) "Arquivo do Estado de São Paulo: pontos básicos de reforma." b) "Documentação missioneira no Instituto de Estudos Brasileiros da Universidade de São Paulo". c) "Arquivos particulares". Pesquisa individual em andamento: a) Introdução e notas ao "Diário do Governo" do Morgado de Mateus. b) São Paulo e Angola no século XVIII: correspondência de governadores. Pesquisa de grupo em andamento: Levantamento Bibliográfico de História e Economia brasileiras referente ao perfodo de 1920/1960.

Colaboradores: Profa. Dra. Arlinda Rocha Nogueira e Profa. Dra. Lucy Maffei Hutter.

\section{Atividade de Pesquisa da Profa. Dra. Lucy Maffei Hutter:}

Pesquisa individual concluída: $\mathbf{A}$ atuação de instituiçōes nacionais e italianas vinculadas ao movimento imigratório em São Paulo durante os lustros iniciais do século XX. Pesquisa individual em andamento: Imigração italiana em São Paulo de 1902 a 1914. Pesquisa de grupo concluída: Levantamento dos manuscritos das Coleções Lamego e J. F. de Almeida Prado relativos às história de São Paulo. Colaboradora: Arlinda Rocha Nogueira. Pesquisa de grupo em andamento: Levantamento Bibliográfico de História e Economia Brasileiras referente ao período de 1920/1960. Colaboradores: Profa. Dra. Arlinda Rocha Nogueira e Profa. Dra. Heloísa Liberalli Bellotto.

\section{Atividade de Pesquisa do Prof. Dr. José Eduardo Marques Mauro:}

Pesquisa individual: 0 comportamento da Economia na Era Vargas.

\section{Atividade de Pesquisa da Lic. Dulce Helena Álvares Pessoa Ramos:}

(Profa. Assistente do Departamento de História da Faculdade de Filosofia, Letras e Ciências Humanas - Universidade de São Paulo, realizando estágio no Instituto de Estudos Brasileiros). Pesquisa individual em andamento: a) A Guerra dos Cabanos como expressão de violência social. b) A contribuição da pesquisa histórica no processo de catalogação das fontes primárias do Arquivo da Secretaria da Fazenda. c) 0 acervo particular da familia de Francisco Escobar. Pesquisa de grupo em andamento: Formação de um Arquivo sobre os diversos grupos religiosos do Brasil, com base em informação coletada em periódicos das várias regiōes do país. (Trabalho de pesquisa programado e dirigido pelo Prof. Dr. Duglas Teixeira Monteiro, da Faculdade de Filosofia, Letras e Ciências Humanas - Universidade de São Paulo). 


\section{II - ÁREA DE GEOGRAFIA E ANTROPOLOGIA}

\section{Atividade de pesquisa da Bel. Ruth Brito Lêmos Terra:}

Pesquisa individual concluída: a) Tema do "Ermita e o Anjo", versificado em folheto no Nordeste. b) Métodos para classificação de narrativas populares. c) Pesquisa bibliográfica sobre cultura popular e folclórica: 1) Nos Institut des Hautes Études en Amerique Latine, Institut d'Ettudes Portugais et Bresiliens e Institut d'Etudes Hispaniques, em Paris. 2) Na Biblioteca Comunal e no Istituto Ernesto de Martino, de Folclore, em Milão. Pesquisa individual em andamento: sobre tema das "Mil e Uma Noites", versificado em folheto no Nordeste.

\section{III - AREA DE LETRAS E LINGÜISTICA}

\section{Atividade de Pesquisa da Profa. Dra. Cecilia de Lara:}

Pesquisa individual concluída: a) Edição crítica de Pathé-Baby, de A. de Alcântara Machado. b) Edição crítica teatral de A. de Alcântara Machado. Pesquisa individual em andamento: Levantamento da produção jornalística de A. de Alcântara Machado para organização de futuras ediçōes.

\section{Atividade de Pesquisa da Profa. Dra. Telê A. Porto Ancona Lopez:}

Pesquisa individual concluída: a) Levantamento e organização do material para os Apêndices da edição crítica de Macunaíma, de Mário de Andrade. b) Pesquisa para a organização do curso: Análise e interpretação de Macunaíma o herói sem nenhum caráter de Mário de Andrade. c) Pesquisa para as exposiçōes: Mário de Andrade: "Turista aprendiz/l Aprendiz de Fotógrafo" e "Mário de Andrade: viagens etnográficas' do turista aprendiz". d) Elaboração de catálogo relacionando os materiais das exposiçōes acima referidas. Pesquisa individual em andamento: a) "A presença das Vanguardas na Obra de Mário de Andrade". b) "Estudo do Jornalismo de Mário de Andrade". Pesquisa de grupo em andamento: "Estudo da Marginália de Mário de Andrade", envolvendo alunos de pós-graduação.

\section{Atividade de Pesquisa da Lic. Yêdda Dias Lima:}

Pesquisa de grupo em andamento: Pesquisa sobre os éditos e inéditos das academias, atos acadêmicos e festejos públicos comemorativos de 1641 a $1820 / 22$, sob a direção e orientação do Prof. Dr. José Aderaldo Castello e com a colaboração do Prof.Dr.Isaac Nicolau Salum, para a fixação dos textos em latim. Pesquisa individual projetada: continuação da fase inicial de fichamento de obras gerais sobre o Barroco, poética e oratória. Pesquisa de grupo projetada: a) Leitura do microfilme e estabelecimento do texto da Academia Brasilica dos Renascidos. b) Junto ao Setor de Literatura Brasileira do IEB, levantamento bibliográfico de Literatura Brasileira, referente às décadas de 20,30 , 40 e 50.

\section{IV - ÁREA DE ARTES E ARQUITETURA}

\section{Atividade de Pesquisa da Arquiteta Marta Rossetti Batista:}

Pesquisa individual concluída: Anita Malfatti - Vida e Obra. Pesquisa individual em andamento: coleta de material bibliográfico para a pesquisa "Os Brasileiros na Escola de 
Paris". Pesquisa de grupo em andamento: Documentação das peças de artes plásticas que integram o Acervo Mário de Andrade e elaboração do catálogo do Acervo. Colaboradora: Lic. Yone Soares de Lima.

\section{Atividade de Pesquisa da Lic. Yone Soares de Lima:}

Pesquisa individual concluída: a) Monteiro Lobato - biografia. Ilustrador de sua própria obra literária. Experiência nas artes plásticas. b) Revistas: Leitura e fichamento: levantamento de matéria sobre ilustração: 0 Brasil Artístico R. J., 1911); Estética (R. J., 1924); A Revista (B. H., 1925); Revista Nacional (S. P., 1921); Problemas (S.P., 1927); Vamos Lerl (R.J., dećadas de 30 e 40); Forma (México, 1928); Compás (Buenos Aires, s/d). Pesquisa individual em andamento: a) Os retratos de Mário de Andrade em sua coleção de Artes Visuais. b) A ilustração em São Paulo, década de 20. c) Revistas . estrangeiras na Biblioteca de Mário de Andrade. Pesquisa de grupo em andamento: Documentação das peças de artes plásticas que integram o Acervo de Mário de Andrade e elaboração do catálogo do Acervo. Colaboradora: Arquiteta Marta Rossetti Baptista.

\section{SETOR CULTURAL}

Sob a chefia do Conselheiro Prof. Dr. José Aderaldo Castello, abrange cursos, projeções, conferências, exposiçð̄es, publicações, intercâmbio, bolsas.

\section{Cursos}

VII Curso de Férias sobre Cultura Brasileira. Período de 14 a 18 de fevereiro. Programa: século XVIII e o Barroco no Brasil (29 parte). Coordenador: Prof. Dr. José Aderaldo Castello. Promoção: Instituto de Estudos Brasileiros - Universidade de São Paulo. Patrocínio: Coordenadoria de Atividades Culturais - Universidade de São Paulo. Conferencistas: Prof. Virgnlio Noya Pinto, Prof. Egon Schaden, Prof. Francisco Vital Luna, Profa. Myriam Ellis, Prof. Iraci Del Nero Costa, Profa. Leima Mesgravis, Prof. Aziz Nacib Ab'Saber, Prof. Wolfgang Pfeiffer, Prof. José Aderaldo Castello, Profa. Yêda Dias Lima. Prof. Hélio Lopes, Prof. Benedito Lima de Toledo e Prof. Olivier Toni.

\section{Conferências}

Conferências realizadas pelo Prof. Jean Roche, da Universidade de Toulouse, França, sobre João Cabral de Mello Neto e sobre o Romance Modernista, em agosto.

\section{Exposiçōes}

- Cooperação como o Departamento de Bibliotecas Públicas da Prefeitura do Município de São Paulo para a realização da exposição "Mário, aprendiz de fotógrafo", comemorativa do nascimento de Mário de Andrade, em outubro.

- Organização e patrocínio, juntamente com o Museu de Arte Contemporânea da Universidade de São Paulo, da Exposição Retrospectiva da Anita Malfatti, insugurada dia 10 de novembro.

\section{Publicagōes}

- Revista do Instituto de Estudos Brasileiros, no 19, empenhada em 1977.

- Pronunciamento de Professores, Brasilianistas e Escritores Estrangeiros e Brasileiros sobre o Instituto de Estudos Brasileiros, mimeografado em 1977, com 104 páginas. 


\section{Intercâmbio}

- Reunião com Coordenadores do Programa de "Estudos de Problemas Brasileiros" de todas as unidades da Universidade de São Paulo, em atendimento ao Of. SG/68, do Senhor Coordenador da Câmara de Graduação, Prof. Dr. Antônio Guimarães Ferri, em abril, para estudo da situação geral da execução dos programas nas respectivas unidades. Dessa reunião foi feito levantamento dando origem ao "Pronunciamento do Conselho de Administração do Instituto de Estudos Brasileiros sobre a Coordenadoria Geral da Disciplina de Estudos Brasileiros na Universidade de São Paulo", em três páginas, e "Sinopse da Situação da Disciplina Estudos Brasileiros na Universidade de São Paulo - Campus da Cidade Universitária Armando de Salles Oliveira" mais o "Apêndice" num total de cinqüenta e oito páginas, encaminhados ao DD. Coordenador da Câmara de Graduação, em maio.

- Colaboração com o Centro de Estudos Rurais e Urbanos, sob a direção da Profa. Dra. Maria Isaura Pereira de Queiroz, para a pesquisa "Levantamento da Obra Brasileira de Roger Bastide" que constituirá o Arquivo Roger Bastide a ser organizado por este Instituto, para posterior publicação das "Obras Completas de Roger Bastide".

- Recepção a vinte e quatro professores universitários americanos, Grupo Georges Consortium Brazil Faculty Development Seminar, ligados aos Estudos Brasileiros e liderados pelo Prof. Park RENSHAW, de 26 de julho a 1 o de agosto, que visitaram a Universidade de São Paulo, a Universidade Estadual de Campinas e o Instituto Agronômico de Piracicaba-USP.

\section{Bolsistas}

- Bolsistas estrangeiros, da área de Literatura Brasileira, que realizam estágio no Instituto de Estudos Brasileiros, sob a orientação dos Profs. Drs. José Aderaldo Castello, Cecilia de Lara e T. A. Porto Ancona Lopez.

- Marie-Joséphe Diata, de nacionalidade senegalesa.

- Sung Doc Lee, de nacionalidade coreana.

- Antônio Rodrigues Baptista, de nacionalidade portuguesa.

- Brigitte Luppi, de nacionalidade francesa.

- Sylvie Raynal-Lesot, de nacionalidade francesa. 